\title{
PREPARATIONS AND CHARACTERIZATIONS OF SUPER-HYDROPHOBIC SURFACES ON Al ALLOYS AND THEIR ANTI-ICING PROPERTIES
}

\author{
PRIPRAVA IN KARAKTERIZACIJA SUPERHIDROFOBNIH \\ POVRŠIN NA Al ZLITINAH IN NJIHOVE PROTIZALEDENITVENE \\ LASTNOSTI
}

\author{
Hairong Gao', Ruiying Wang², Haijie Sun¹, Aijuan Zhao', Ling Wang1 \\ 1Zhengzhou Normal University, School of Chemistry and Chemical Engineering, Zhengzhou 450044, Henan, China \\ ${ }^{2}$ Henan Vocational College of Chemical Technology, School of Chemistry and Chemical Engineering, Zhengzhou 450042, Henan, China \\ sunhaijie406@zznu.edu.cn
}

Prejem rokopisa - received: 2017-07-25; sprejem za objavo - accepted for publication: 2017-11-15

doi:10.17222/mit.2017.125

\begin{abstract}
A low-cost and simple methodology is successfully developed for the preparation of super-hydrophobic surfaces on Al alloys by a facile hydrothermal reaction method at $60^{\circ} \mathrm{C}$ after a simple chemical modification. Using such a robust method, a relatively large contact angle of $167^{\circ}$ and a small roll angle of $3^{\circ}$ can be achieved. The icing behavior of the surfaces was investigated in $-10{ }^{\circ} \mathrm{C}$ environment. It is found that such super-hydrophobic surfaces exhibit remarkable anti-icing characteristics. In particular, the icing time on the surfaces can be delayed considerably. Therefore, our study suggests that the present methodology and the prepared super-hydrophobic surfaces could be applied in various engineering fields.

Keywords: Al alloys, contact angle, icing, super-hydrophobic, anti-icing

Avtorji prispevka so uspešno razvili enostavno metodologijo za pripravo super hidrofobnih površin na Al zlitinah z enostavno metodo hidrotermalne reakcije pri $60^{\circ} \mathrm{C}$ po enostavni kemični modifikaciji. Z uporabo te robustne metode so dosegli relativno velik kontaktni kot $167^{\circ}$ in kotalni kot manjši od $3^{\circ}$. Proti- zamrzovalne lastnosti površin so ugotavljali v okolju pri $-10^{\circ} \mathrm{C}$. Ugotovili so, da imajo takšne super hidrofobne površine odlične lastnosti, ki preprečujejo zamrzovanje oz. zaledenitev. Se posebej je dosežena pomembna zakasnitev časa zaledenitve na teh površinah. Avtorji tega prispevka zato ugotavljajo, da je predstavljeno metodologijo in pripravljene površine možno uporabiti na različnih inženirskih področjih.

Ključne besede: Al zlitine, kontaktni kot, zdrs, super hidrofobnost, preprečevanje zaledenitve
\end{abstract}

\section{INTRODUCTION}

The accumulation of ice on exposed surfaces may cause serious problems to the integrity of outdoor equipment such as high-voltage cables, wind-turbine blades, buildings, telecommunication towers and aircraft. Two main strategies can be used to deal with this issue. One is active deicing methods, and another is passive methods. ${ }^{1,2}$ Current active deicing methods usually based on melting or breaking of already formed ice layers. In addition to their undesired weight and design complexity, active anti-icing approaches require substantial energy for operation. The passive methods based on protecting the exposed surface by elaborating coatings with ice-phobicity characteristics to significantly extend the freezing time and reduce the ice adhesion strength. Compared to active methods, passive ones are environmentally friendly and low-cost. Passive ice-phobic coatings have also been proposed during the past decades, yet the expected results have not been achieved. . $^{3,4}$

To protect exposed surfaces against excessive ice accumulation, ice-phobic coatings must be highly reliable and durable. While some coatings have excellent ice-phobic properties, the balance between ice-phobic characteristics, excellent mechanical properties and actual application value is required. Growing films directly from a substrate considerably improves the adherence and the mechanical stability of the resulting films, comparing with colloidal-deposition techniques. ${ }^{5}$ However, as far as we know, there has been almost no research of the in-situ growth of the ice-phobic film with micro/nanoscale binary structure on aluminum substrates up to now.

In recent years, the achievement of the "Lotus effect" super-hydrophobic surface research made people see the light of overcoming anti-icing difficulties. Inspired by the outstanding super-hydrophobicity and self-cleaning property of lotus leaf, the wettability of solid surfaces has several applications in reducing the resistance shell of submarines, ships, resisting water coalescence and fog condensation, preventing the obstruction of the oil pipes, micro-injection needle, and being catalysts, optical and sensors, with the increasing biocompatibility, lubricity, and durability. ${ }^{6-8}$

Contact angle (CA) and sliding angle (SA) are two indexes for the evaluation of wettability. In general, the super-hydrophobic surface has a water contact angle 
greater than $150^{\circ}$ and a very low sliding angle, typically below $10^{\circ} \cdot{ }^{9-12}$ Different kinds of engineered super-hydrophobic surfaces have been created on various metal substrates, such as gold, ${ }^{13}$ silver, ${ }^{14}$ copper, ${ }^{15-18}$ alloy, ${ }^{19,20}$ and stainless steel. ${ }^{21,22}$ The super-hydrophobicity and ice-phobicity of aluminum surfaces have also attracted more interest because of their practical or potential applications. ${ }^{23-31}$ Several groups have studied the adhesion of ice on super-hydrophobic surfaces and found good correlations between the hydrophobicity of surfaces and their ice-phobic behaviour. ${ }^{32-35}$ Layered double hydroxides (LDHs), also well known as anionic clays or hydrotalcite-like materials, are an important kind of layered materials. The composition of LDH can be represented by the general formula $\left[\mathrm{M}_{1-x}^{2+} \mathrm{M}_{x}^{3+}(\mathrm{OH})_{2}\right]^{x+}\left(\mathrm{A}^{n-}\right)_{x / n} \cdot m \mathrm{H}_{2} \mathrm{O}$, where the metal cations $\mathrm{M}^{2+}$ and $\mathrm{M}^{3+}$ occupy the octahedral holes in a brucite-like layer and the anion $\mathrm{A}^{\mathrm{n}-}$ locates in the hydrated galleries between the layers. ${ }^{36,37}$

This paper presented a very simple, time-saving, and inexpensive method for growing $\mathrm{Zn}-\mathrm{Al} \mathrm{LDH}$ nanowalls and bayerite microrods on aluminum substrates in situ. Aluminum substrates were employed to provide $\mathrm{Al}^{3+}$ for the growth of $\mathrm{Zn}-\mathrm{Al} \mathrm{LDH}$ and bayerite as well as to collect relatively ordered micro/nanostructures rather than random powders in the synthetic process. The resulting film changed from super-hydrophilic and easy icy to super-hydrophobic and ice-phobic after modified stearic acid.

\section{EXPERIMENTAL PART}

\subsection{Materials}

All the reagents in the experiment were analytical grade and used without further purification. Al sheets with a size of $20 \mathrm{~mm} \times 20 \mathrm{~mm} \times 0.15 \mathrm{~mm}$ were cut from a rolled sheet (99\%, Shanghai, Chemical Reagent Co.,China), Zinc acetate $\left[\mathrm{Zn}\left(\mathrm{CH}_{3} \mathrm{COO}\right)_{2}, 99 \%\right.$, Tianjin, Chemical Reagent Co., China], ammonia (25-28 \%), and stearic acid. Deionized water was exclusively used in all aqueous solutions and rinsing procedures.

\subsection{Preparation of super-hydrophobic surfaces}

In a typical process, Al sheets were dipped into acetone and deionized water and cleaned by ultrasonic washer. Any substances physically and weakly attached to the substrate after the reaction was removed during ultrasonication for $3 \mathrm{~min}$. Then, they were immersed in a 1.5-M aqueous solution of $\mathrm{NaOH}$ for $1 \mathrm{~min}$ to get rid of the surface impurity, and completely washed with deionized water. In a typical experimental procedure, $0.00125 \mathrm{~mol} \mathrm{Zn}\left(\mathrm{CH}_{3} \mathrm{COO}\right)_{2} \cdot 2 \mathrm{H}_{2} \mathrm{O}$ was added into 100 $\mathrm{mL}$ of deionized water under vigorous magnetic stirring to form a homogeneous solution. An appropriate amount of ammonia was added to this solution dropwise (the molar ratio of ammonia/ $\mathrm{Zn}^{2+}$ was $0.25: 1-4: 1$ ). The mix- ture solution became turbid with the adding ammonia. Meanwhile, a milk-like white solution was obtained, which was then transferred into a Teflon-lined stainlesssteel autoclave. The cleaned Al sheets were vertically placed in the reaction solution. The autoclave was sealed tightly and maintained at $60{ }^{\circ} \mathrm{C}$ for $5 \mathrm{~h}$. After the reaction, the $\mathrm{Al}$ sheet was taken out, washed with deionized water and dried in the air. To achieve surface super-hydrophobicity, the as-prepared films were immersed in an $\mathrm{n}$-hexane solution of $5-\mathrm{mM}$ stearic acids for $5 \mathrm{~h}$ at room temperature. Finally, the modified substrates were rinsed with ethanol 3 times and then dried in the air at room temperature.

\subsection{Delay time experiment}

The reference drops $\left(8 \mu \mathrm{L}, 21{ }^{\circ} \mathrm{C}\right.$, tap water) were placed on these surfaces and the temperature was controlled at $-10^{\circ} \mathrm{C}$, and observed in situ by a digital camera. Initially, these drops were all transparent on the surfaces. As the time passed, the drops on the surfaces were frozen and became non-transparent. The delay times (DTs) ${ }^{35}$ were defined as the time that the drop changed from a water drop to tiny ice cubes. The three surfaces (untreated Al sheet, Zn-Al LDH super-hydrophobic surface, bayerite/Zn-Al LDH super-hydrophobic surface) were observed in situ at the same time, the delay times were recorded and values were an average of five times. The room temperature and relative humidity were $22 \pm 2{ }^{\circ} \mathrm{C}$ and $60 \pm 5 \%$, respectively.

\subsection{Ice-adhesion force measurement}

The ice-adhesion evaluation tests of the above-mentioned three samples were conducted in a Spinner Coater (Figure 1). The nozzle of a commercially available manual sprayer equipped with tap water was kept at about $8 \mathrm{~cm}$ from the substrates, and the tap water was sprayed until the surface was fully covered with a liquid layer, and then placed the substrates covered with liquid layer in refrigerator at $-10{ }^{\circ} \mathrm{C}$ until frozen. The spinning speed was gradually raised to spin off the ice on the substrate surfaces; the accurate rotating speed could be obtained from the display screen of the Spinner Coater. Ice mass and area were carefully evaluated and recorded. The masses of the glass slide $\left(m_{1}\right)$, the substrate $\left(m_{2}\right)$ and the substrate covered with ice $\left(\mathrm{m}_{3}\right)$ were measured in turn, the ice mass $(m)$ was calculated as $m=m_{3}-m_{2}-$ $m_{1}$. The artificially iced samples were then spun in the Spinner Coater placed in a refrigerator at $-10{ }^{\circ} \mathrm{C}$ to determine the speed at which ice detachment from the sample surface occurred. At the moment of the detachment, the adhesion strength of ice was assumed to be equal to the centripetal force, $F=m v^{2} / r$, where $\mathrm{m}$ is the ice mass, $\mathrm{v}$ is the rotation speed and $\mathrm{r}$ is the distance between $\mathrm{Al}$ sheet and the center. The shear stress, correspondingly, was calculated as $\tau=F / A$, where $A$ is the de-iced area and equal to the area of the substrate. 


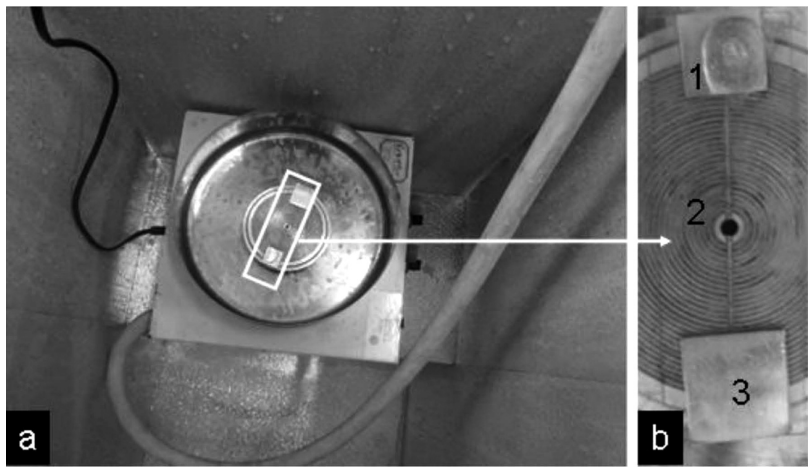

Figure 1: a) Prepared sample in spinner coater set-up measuring ice adhesion, b) partial enlarged drawing: 1) sample, 2) glass slide and 3) Al sheet of equal mass with sample.

The adhesion reduction factor, $\mathrm{ARF},{ }^{29}$ was calculated as the ratio of ice shear stress on the untreated $\mathrm{Al}$ sheet to the treated $\mathrm{Al}$ sheet, which could reduce effectively the influence of experimental errors.

\subsection{Characterizations}

The phases of the samples were characterized with $\mathrm{X}$-ray powder diffraction (XRD) using the Rigaku $\mathrm{D} / \mathrm{max} 2500$ diffractometer with $\mathrm{Cu}-K_{\alpha}$ radiation $(k=$ $0.15406 \mathrm{~nm}$ ). The surface morphology was observed using a JOEL JSM-6610LV scanning electron microscope. Static contact angles and sliding angles were measured based on the sessile drop measuring method with $5-\mu \mathrm{L}$ droplets of distilled water using a Model 250 (p/n 250-F1) goniometer (ramé-hart instrument Co., USA) at ambient temperature. The average CA was obtained by measuring the same sample at five different positions and every position 15 times. The sliding-angle measurements were carried out using a mechanical level goniometer, which recorded when the deposited water droplet started to roll off. The temperatures of the sample surfaces and the environment were recorded by an Infrared Thermometer (CASON-CA390). Ice-phobic properties were studied by using a refrigerator (Mei Ling, China). Ice-adhesion strengths were evaluated using a Spinner Coater (KW-4A) referred to the centrifuge adhesion test (CAT) method. ${ }^{29}$

\section{RESULTS AND DISCUSSION}

\subsection{Formation of micro/nanoscale hierarchical struc- tures}

Figure 2 shows the SEM images of the prepared films using different molar ratios between $\mathrm{Zn}\left(\mathrm{CH}_{3} \mathrm{COO}\right)_{2}$ and $\mathrm{NH}_{3} \cdot \mathrm{H}_{2} \mathrm{O}$ with different magnifications. It can be seen from Figures $\mathbf{2 a}, \mathbf{2 b}, \mathbf{2 c}$ ) that there are two different morphologies: one is 3D flowerlike microspheres with diameters of $5-20 \mu \mathrm{m}$ and the sheet thickness of the microspheres is about $50 \mathrm{~nm}$; the other is a homogeneous nanowalls structure. The panoramic morphology shows that the film is also composed of flower-like protrusions (Figure 2d) with diameters of 5-20 $\mu \mathrm{m}$ when the ammonia concentration doubled (Figure 2e), but the flat area with the thickness $100 \mathrm{~nm}$ of the nanowalls become more porous (Figure 2f). With the increasing of the concentration of ammonia, the film preferentially grow on the $\mathrm{Al}$ surface, forming a pattern of high resolution, is constructed with stacked nanosheets of about $50 \mathrm{~nm}$ in thickness, resulting in a highly porous surface (Figure $\mathbf{2 g}$ and $\mathbf{2 h}$ ).

We found that the concentration of ammonia plays a vital role in tailoring the morphologies of the resultant films (Figure 3). It is clear that the resulting surface exhibits two shapes of architectures. One is flower-like club-shaped microrods, another is nanowall porosity. Flower-like club-shaped and porous architectures are different with the change of molar ratios between $\mathrm{Zn}\left(\mathrm{CH}_{3} \mathrm{COO}\right)_{2}$ and $\mathrm{NH}_{3} \cdot \mathrm{H}_{2} \mathrm{O}$. The microrods have the shape of stepped construction. We can see that the flower-like microspheres have disappeared and become
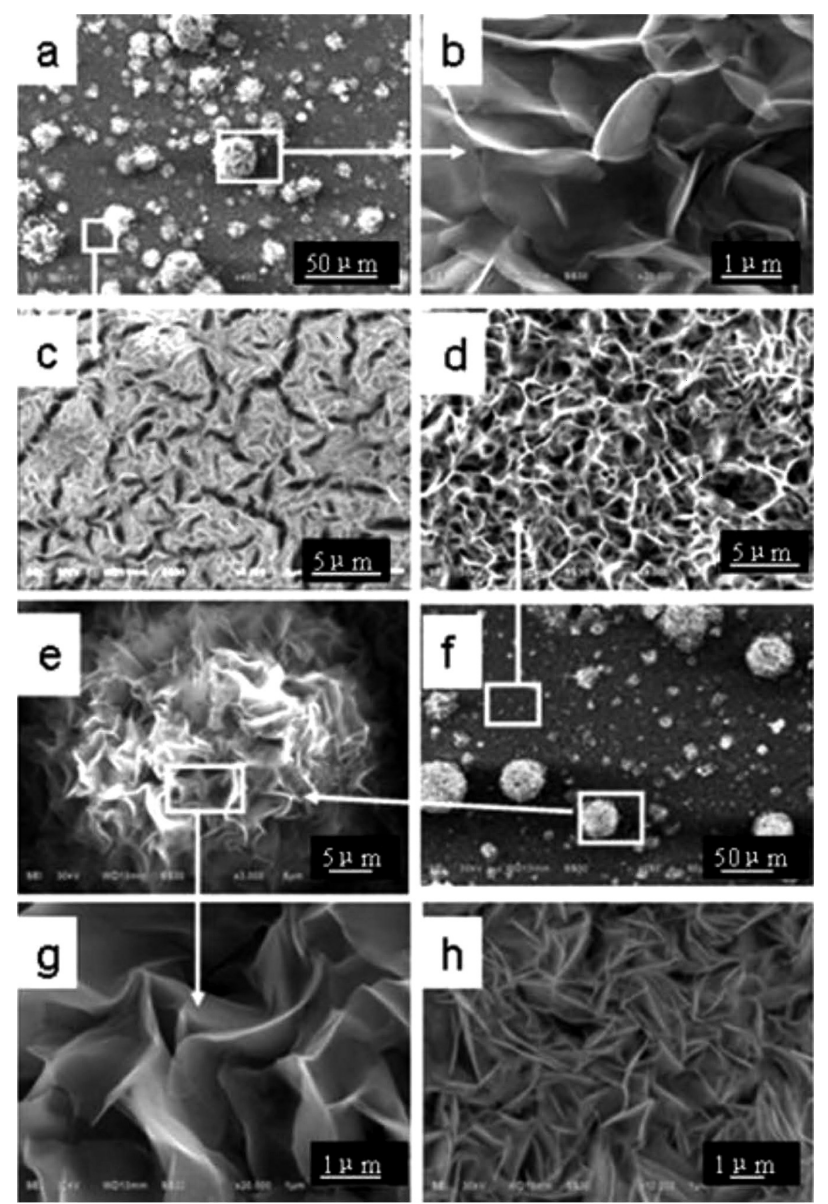

Figure 2: SEM images of: a) the prepared film at low magnification under ammonia $/ \mathrm{Zn}^{2+}=0.25$, b) the sphere at high magnification, c) the flat area at high magnification, d), e) high-magnification image of flat area and a hemispherical protrusion, respectively, f) the prepared film at low magnification under ammonia/ $\mathrm{Zn}^{2+}=0.5: 1, \mathrm{~g}$ ) higher-magnification images of the surface, $h$ ) the prepared film under ammo$\mathrm{nia} / \mathrm{Zn}^{2+}=0.75: 1$ 


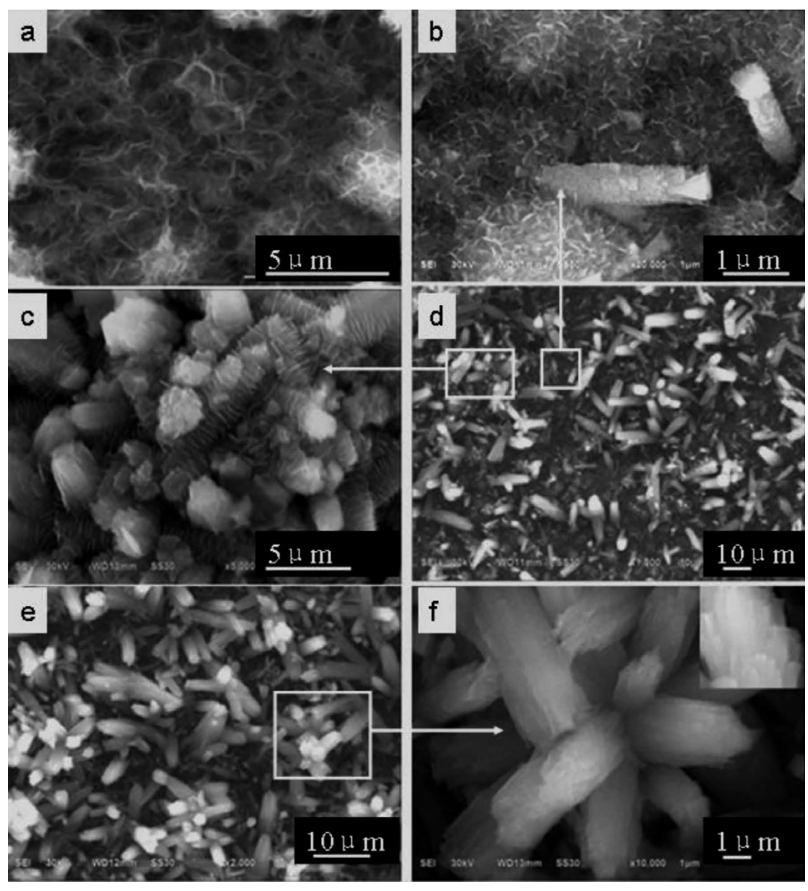

Figure 3: SEM images of the resultant films prepared at various molar ratios of ammonia/ $\mathrm{Zn}^{2+}$ of: a) $1: 1$; b), c), d) $1.25: 1$, e), f) $1.5: 1$ while the reaction time was $5 \mathrm{~h}$ and the reaction temperature was $60{ }^{\circ} \mathrm{C}$

more porous when the molar ratio of ammonia/ $\mathrm{Zn}^{2+}$ increases to 1:1 from Figure 3a. When the molar ratio of ammonia/ $\mathrm{Zn}^{2+}$ is increased to $1.25: 1$, the flower-like microspheres disappear and the microrods begin to appear (Figure 3b). From the high-resolution image of the bottom of the microrods (Figure 3c), it can be seen that the microrods along with the relatively flat regions grow on the curly nanowalls; the nanowalls are uniformly crooked and assemble into a porous structure. From the high-resolution image of the top of the microrods (Figure 3d), we can see that the microrods are uniform wound by extremely thin nanosheet-like crystallites even construct a tower-like superstructure. When the molar ratio of ammonia/ $\mathrm{Zn}^{2+}$ is further increased to $1.5: 1$, densely packed microrods grow on the nanowalls in situ and almost cover it (Figure 3e). From the highresolution image of the top of the flower-like microrods (Figure 3f), it can be seen that the surface of each microrod is not smooth but scraggly and even construct the shape of a stepped superstructure. We can infer that the SEM images showing the prepared surface is composed of micro/nanoscale binary structure, which is similar to the structure of a lotus leaf.

Figure 4 shows the X-ray diffraction (XRD) patterns of the as-prepared $\mathrm{Zn}-\mathrm{Al} \mathrm{LDH}$ film and bayerite/Zn-Al $\mathrm{LDH}$ film on the surface of $\mathrm{Al}$ sheets under the different molar ratios of the ammonia/ $\mathrm{Zn}^{2+}$. For comparison purposes, the XRD pattern of the pure $\mathrm{Al}$ sheet was also recorded, as shown in Figure 4a. We can see in Figure 4b that the hierarchical structures can be determined by the mixture of $\mathrm{Zn}_{6} \mathrm{Al}_{2}(\mathrm{OH})_{16} \mathrm{CO}_{3} \cdot 4 \mathrm{H}_{2} \mathrm{O}$ (JCPDS 38-0486;

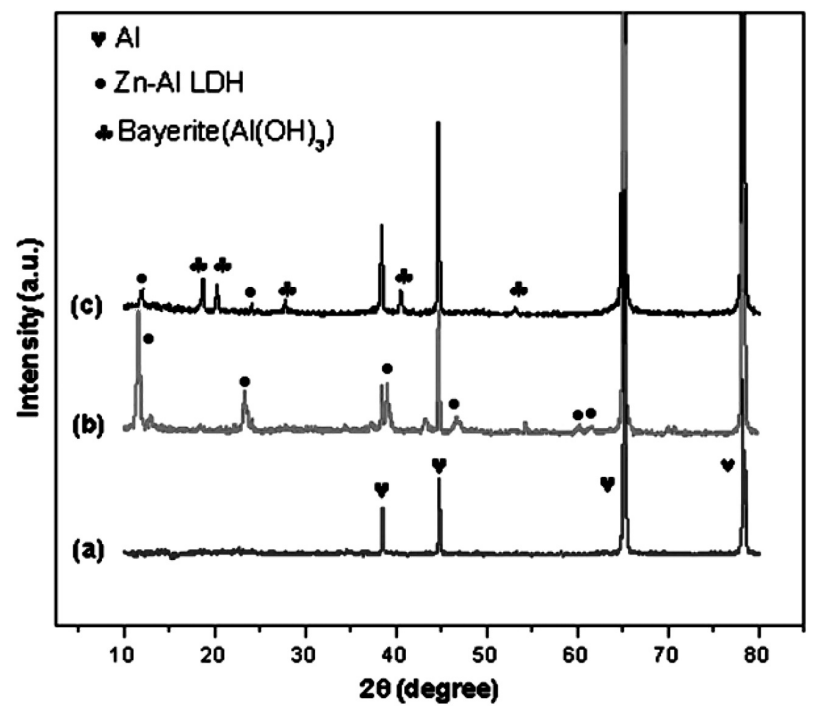

Figure 4: XRD patterns of: a) the pure Al sheet, b) the $\mathrm{Zn}-\mathrm{Al} \mathrm{LDH}$ film on $\mathrm{Al}, \mathrm{c}$ ) bayerite/Zn-Al LDH films on $\mathrm{Al}$

space group $R \overline{3} \mathrm{~m}, A=0.3076 \mathrm{~nm}, c=2.280 \mathrm{~nm})$. The strong peaks at $11.54^{\circ}, 23.28^{\circ}, 39^{\circ}$ and $46.8^{\circ}$, which correspond to the crystal orientation, are (003), (006), (015), and (018), confirming the layer structure of LDH materials. ${ }^{38}$ The diffraction peaks in Figure $4 \mathbf{c}$ show the strong peaks at $18.78^{\circ}, 20.20^{\circ}, 27.82^{\circ}, 40.52^{\circ}$, and $53.12^{\circ}$, which correspond to the bayerite phase according to PDF card no. 20-0011. ${ }^{39}$ The X-ray and the SEM results indicated that $\mathrm{Zn}-\mathrm{Al} \mathrm{LDH}$ films grew on the surface of $\mathrm{Al}$ sheet first, and then transformed into microrod bayerite films gradually with the increasing molar ratio of the ammonia/ $\mathrm{Zn}^{2+}$. From careful analyses the peak at $11.85^{\circ}, 23.68^{\circ}$ and the SEM (Figure 3d), we can get the information that there are some $\mathrm{Zn}-\mathrm{Al} \mathrm{LDH}$ nanowalls mixing in bayerite microrods when the molar ratio of the ammonia/ $\mathrm{Zn}$ was 1.25:1.

The Al sheets play an important role in the formation of the hierarchical $\mathrm{Zn}$-Al LDH and bayerite micro/nanoscale structures, which is employed in the synthetic process to provide $\mathrm{Al}^{3+}$ for the growth of $\mathrm{Zn}-\mathrm{Al} \mathrm{LDH}$ and bayerite in situ and to collect relatively ordered micro/ nanoscale hierarchical structures rather than random powders. Conventionally, $\mathrm{Zn}-\mathrm{Al} \mathrm{LDH}$ are prepared by the coprecipitation of solutions of $\mathrm{Zn}^{2+}$ and $\mathrm{Al}^{3+}$ salts with alkali, followed by aging at a certain temperature for a period of time. In that case, the prepared films are usually aggregates composed of many platelet-like 2D LDH nanocrystallites, without preferential orientation. Herein, the Al substrate was introduced to the experiments to solve this problem as well as improve the adhesion of the film and the substrate effectively. These experiments results confirmed that the formation of hydrotalcite-like compounds and bayerite on the Al sheets is linked to the chemical reactions at the interface. ${ }^{40,41}$

$$
\mathrm{NH}_{3} \cdot \mathrm{H}_{2} \mathrm{O}=\mathrm{NH}_{4}^{+}+\mathrm{OH}^{-}
$$




$$
\begin{gathered}
2 \mathrm{Al}+2 \mathrm{OH}^{-}+6 \mathrm{H}_{2} \mathrm{O}=2 \mathrm{Al}(\mathrm{OH})_{4}^{-}+3 \mathrm{H}_{2} \\
\mathrm{Zn}^{2+}+4 \mathrm{OH}^{-}=\left[\mathrm{Zn}(\mathrm{OH})_{4}\right]^{2-} \\
\mathrm{Al}(\mathrm{OH})_{4}^{-}+\left[\mathrm{Zn}(\mathrm{OH})_{4}\right]^{2-} \mathrm{CO}_{3}^{2-}+\mathrm{H}_{2} \mathrm{O}=\mathrm{Zn}-\mathrm{AlLDH} \\
\mathrm{NH}_{4}^{+}+\mathrm{CH}_{3} \mathrm{COO}^{-}=\mathrm{CH}_{3} \mathrm{COOH}+\mathrm{NH}_{3} \\
\mathrm{Al}(\mathrm{OH})_{4}^{-}+\mathrm{CH}_{3} \mathrm{COO}=\mathrm{Al}(\mathrm{OH})_{3}+\mathrm{CH}_{3} \mathrm{COO}^{-}+\mathrm{H}_{2} \mathrm{O}
\end{gathered}
$$

As we can see, two major stages are involved in our synthetic process. The growth of well-defined arrays of 2D LDH in situ is the first stage. At the initial stage, $\mathrm{NH}_{3} \cdot \mathrm{H}_{2} \mathrm{O}$ becomes dissociated (Equation (1)). The dissolving $\mathrm{Al}$ surface is a prerequisite to start the nucleation and growth of $\mathrm{LDH}$. $\mathrm{Al}(\mathrm{OH})_{4}^{-}$is first formed at the interface by the reaction between $\mathrm{OH}^{-}$and $\mathrm{Al}$ (Equation (2)), at the same time, $\left[\mathrm{Zn}(\mathrm{OH})_{4}\right]^{2-}$ is generated in solution (Equation (3)). The next reaction between $\mathrm{Al}(\mathrm{OH})_{4}{ }^{-}$and $\left[\mathrm{Zn}(\mathrm{OH})_{4}\right]^{2-}$ (Equation (4)) will readily give rise to $\mathrm{Zn}-\mathrm{Al}$ LDH. Apparently, the high nucleation density correlated to the high concentration of $\mathrm{Al}(\mathrm{OH})_{4}{ }^{-}$released from the Al substrate in the interfacial regions plays a very important role in the formation of such oriented nanowalls. The hetero-nucleation and growth of $\mathrm{Al}(\mathrm{OH})_{3}$ microrods is the second stage. The as-formed LDH begins to simply decrease and gradually grow well-ordered $\mathrm{Al}(\mathrm{OH})_{3}$ nanorods (Equations (5) and (6)). The concentration of $\mathrm{OH}^{-}$influences the formed amount of $\mathrm{Al}(\mathrm{OH})_{4}^{-}$. The more $\mathrm{Al}(\mathrm{OH})_{4}^{-}$produced larger porosity on aluminum substrates, so the porosity of $\mathrm{Zn}-\mathrm{Al} \mathrm{LDH}$ became larger and larger with an increase of the concentration of $\mathrm{NH}_{3} \cdot \mathrm{H}_{2} \mathrm{O}$, as shown in Figure 2. But the concentration of $\mathrm{Zn}^{2+}$ gradually fades away and results in the limited growth of $\mathrm{LDH}$, meanwhile, the reaction between $\mathrm{CH}_{3} \mathrm{COO}^{-}$and $\mathrm{Al}(\mathrm{OH})_{4}^{-}$continued and gradually became dominant, which led to a decrease in LDH and an increase in bayerite.

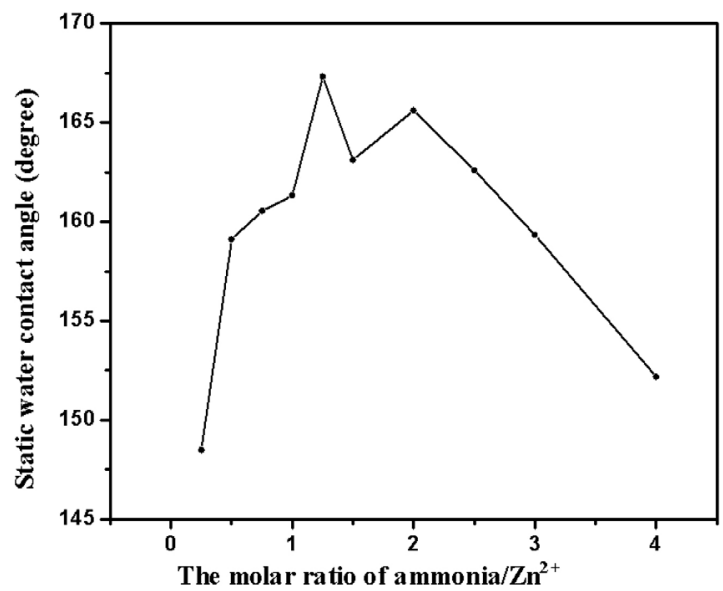

Figure 5: WCA of the resulting surfaces with different molar ratio of ammonia/ $\mathrm{Zn}^{2+}$ in $5 \mathrm{~h}$ reaction time after modified

\subsection{Hydrophobic properties}

Concerning the porous structures of the product, the wettability of the film on the aluminum substrate and the effect of ammonia concentration on the wettability of the film was investigated. Figure 5 indicates that the contact angles changed regularly with increasing the molar ratio of ammonia/ $/ \mathrm{Zn}^{2+}$. We can see that the CA first increases and then decreases slowly with the ammonia concentration increasing. According to the curve, a clear contrast can be found that the molar ratio of 1.25:1 is the best of all. To sum up, the optimal parameters of the preparation of super-hydrophobic surface were obtained. It is found that the wettability of all the surfaces changed from super-hydrophilic to super-hydrophobic after the treatments with stearic acid. Herein, the sample is selected as a typical case. Without chemical modification, the water droplet is adsorbed immediately by the treated surface shows super-hydrophilic $\left(\mathrm{CA}<5^{\circ}\right)$ (Figure 6a) and the original aluminum sheet shows hydrophilic with a water CA $85.2^{\circ}$, as shown in Figure 6a. However, after the simple chemical modification with stearic acid, the water CA increases to $167.3^{\circ}$ (Figure 6b) with a low sliding angle $<3^{\circ}$ (Figure 6c, 6d, 6e, and $\mathbf{6 f}$ ). In addition, the $\mathrm{CA}$ of the untreated surface after modification with stearic acid is $98.2^{\circ}$. Therefore, the changes in the CA observed are due to Al surface roughening not to the stearic acid crystals.

It is well known that the surface roughness plays a key role in determining the super-hydrophobic behavior of a surface. By increasing the surface roughness of the material we can significantly improve the surface hydrophobicity and hydrophilicity. According to previous research, a hierarchical structure can dramatically decrease the area of contact between the liquid and the solid, which can reduce the adhesion of a liquid droplet

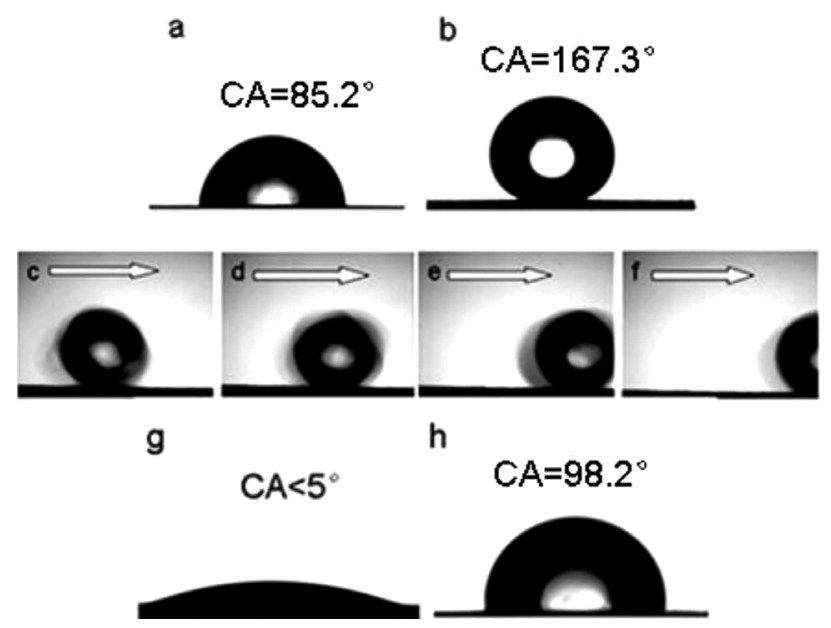

Figure 6: a) the $\mathrm{CA}$ of original $\mathrm{Al}$ sheets, b) The $\mathrm{CA}$ of the treated surface after modification with stearic acid, c), d), e), f) Snapshot photographs of a $5-\mu \mathrm{L}$ water droplet rolling off of the resultant super-hydrophobic surface as the substrate is tilted by $\sim 3.0^{\circ}$, g) the $\mathrm{CA}$ of the treated surface before modification with stearic acid, h) the $\mathrm{CA}$ of the untreated surface after modification with stearic acid 
to the solid surface and sliding angle. Additionally, M. Nosonovsky ${ }^{42}$ demonstrated that a hierarchical roughness could effectively improve the stability of a composite interface. Our group also found out that the secondary structure (i.e., submicrostructure or nanostructure) could effectively resist the droplets into troughs of the rough structures. ${ }^{43,44}$ To explain the super-hydrophobic mechanism of these micro/nanoscale hierarchical structures, here we present a brief theoretical explanation. The super-hydrophobic behavior can be characterized in terms of the Cassie-Baxter model, ${ }^{45}$ which is generally valid for the heterogeneous surfaces composed of air and a solid exhibiting super-hydrophobicity. Cassie and Baxter proposed an equation to describe the relationship between the water CA on a flat surface $(\theta)$ and a rough surface $\left(\theta^{\prime}\right)$ composed of a solid and air (Equation (7)):46

$$
\cos \theta^{\prime}=f_{1} \cos \theta-f_{2}
$$

In this equation, $\mathrm{f}_{1}$ and $\mathrm{f}_{2}$ are the fractional area estimated for the solid and air on the surface, respectively, $f_{1}+f_{2}=1$. The value of $\theta^{\prime}$ and $\theta$ of $\mathrm{Al}$ sheet surface in Figure 6a and $\mathbf{6 b}$ was $167.3^{\circ}$ and $85.2^{\circ}$, successively. From the Cassie-Baxter model, the value of $f_{2}$ is about 0.977. This means that almost the whole surface area is covered by the air. Due to the large fraction of air trapped within the interstices of the hierarchical nanowalls and nanorods, which greatly increase the air/water interface, preventing the penetration of water droplets into the grooves effectively, and resulting in super-hydrophobicity with a low sliding angle. These results indicate that the surface micro/nanoscale hierarchical morphology plays a significant role in the preparation of a super-hydrophobic surface.

\subsection{Ice-phobic properties}

Numerous scientific experiments show super-hydrophobic surfaces can lead to high ice-phobic properties. ${ }^{47}$ Usually, super-hydrophobic films exhibiting a contact angle hysteresis lower than $5^{\circ}$ lead to very high icephobic properties. Reference drops $(8 \mu \mathrm{L})$ are placed on the surfaces in order to observe how long it takes for the
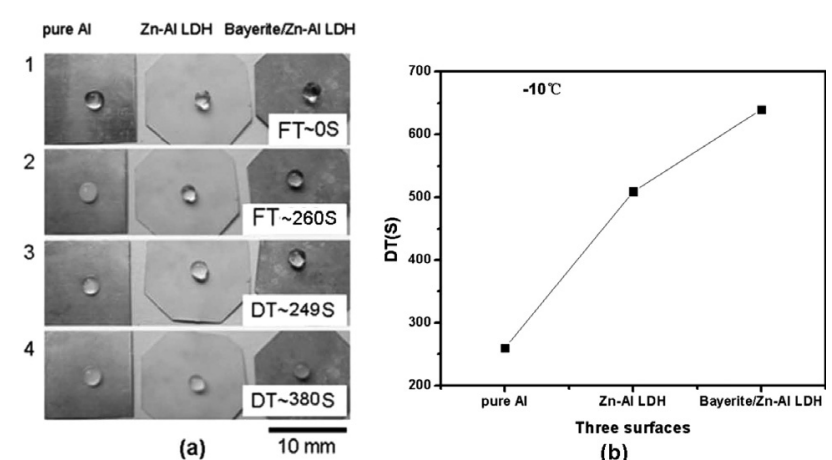

Figure 7: a) In-situ observation of ice formations on pure $\mathrm{Al}, \mathrm{Zn}-\mathrm{Al}$ $\mathrm{LDH}$, and bayerite/Zn-Al LDH surfaces at $-10{ }^{\circ} \mathrm{C}$ with delay times (DT), b) contrast on delay times of ice formation on different surfaces at a sub-zero temperature of $-10{ }^{\circ} \mathrm{C}$ drops to freeze on the cold surfaces. The delay time (DT), the time taken for the drop to freeze, on the surface at $-10^{\circ} \mathrm{C}$ is roughly recorded by observing the non-transparency of the drop. From Figure 7 we can see that all the drops are initially transparent (Frame 1), after freezing time $(\mathrm{FT}) \sim 260 \mathrm{~s}$, the drop on pure Al surface becomes non-transparent (Frame 2). After a DT of $\sim 249 \mathrm{~s}$, two drops are non-transparent, on the pure Al and $\mathrm{Zn}-\mathrm{Al}$ LDH surfaces, respectively (Frame 3). After a DT of about $\sim 380 \mathrm{~s}$, another drop is also non-transparent on the bayerite/Zn-Al LDH surface (Frame 4). We can see that the bayerite/ $\mathrm{Zn}$-Al LDH surface has a much longer DT of $\sim 380 \mathrm{~s}$ than the $\mathrm{Zn}-\mathrm{Al}$ LDH surface with a DT of 249 s. This implies that the differences between the DTs are attributable to the different structural topologies of the surfaces. ${ }^{48}$ As for bayerite/Zn-Al LDH surface, the case of the micro/nanostructure, because of combining both nanostructure and microstructure, a high ratio of trapped-air appears on the micro/nanostructure surface, thus the drop is greatly suspended. Concerning the case of water-condensed drops, the tiny condensed drop, a result of the environment temperature gradient, would first sit on the nano-steps and then grow upwards, and is subsequently suspended onto the microrods with nano-steps to decrease the wet contact with the solid surface. In addition, the thermal conductivity of solid is better than air, so the freezing time of micro/nanoscale hierarchical bayerite/Zn-Al LDH structure with less contact area is longer than pure $\mathrm{Al}$ and $\mathrm{LDH}$, which just coincides with the experiment results.

The ice adhesion was evaluated by spinning the samples at constantly increasing speed until it delaminated. The ice-adhesion reduction factors relative to the type of sample and the corresponding CA and SA are displayed in Figure 8. All the values are averaged on 5 experiments. The adhesion-reduction factors were computed using the following equation: $A F R=\tau_{\mathrm{Al}} / \tau_{\text {film }}$, where $\tau_{\mathrm{Al}}$ and $\tau_{\text {film }}$ are the ice shearing force of pure $\mathrm{Al}$ and treated surfaces. The AFR of $\mathrm{Zn}-\mathrm{Al} \mathrm{LDH}$ and bayerite/Zn-Al LDH surfaces were 3.05 and 8, respectively. From Figure 9 we can see that the surfaces remain active after several ice-shedding events. The morphology of $\mathrm{Zn}-\mathrm{Al}$ LDH and bayerite/Zn-Al LDH surfaces have no changes nearly after the multiple thaw cycles. In addition, the CA of bayerite/Zn-Al LDH surfaces can still reach $156.3^{\circ}$. These results indicated that the prepared super-hydrophobic and ice-phobic surface possessed excellent mechanically and chemically stable properties. While some coatings have greater ice-phobic properties, the balance between mechanical and ice-phobic properties is needed. We found that the adhesion strength of the ice on these samples depends not only on the CA but also on the SA, which has a significant reduction with a decrease of the SA. In comparison with the untreated samples, the super-hydrophobic film on the aluminum surface can effectively mitigate the ice accretion. During ice accumulation, the water droplets did not penetrate the 


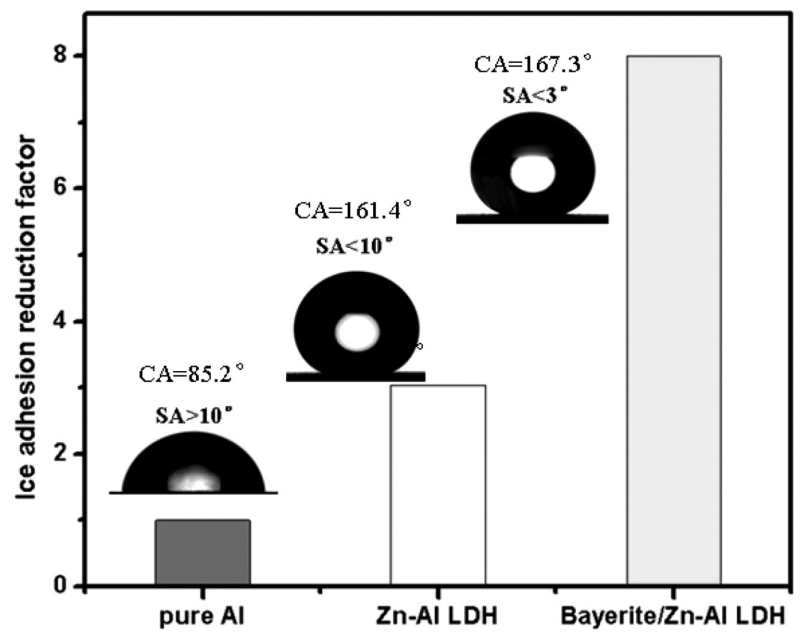

Figure 8: The values of ice adhesion reduction factor (ARF) of three surfaces and the corresponding contact angel (CA) and sliding angle (SA)

micro/nanoscale hierarchical structures, which resulted in air pockets being formed at the ice-solid interface, consequently leading to poor ice-adhesion strengths. Therefore, the higher surface roughness is responsible for super-hydrophobic properties and ice-phobic properties, which can be verified well by the SEM observation and the hydrophobic and ice-phobic results.

\section{CONCLUSIONS}

A super-hydrophobic and ice-phobic surface composed of Zn-Al LDH nanowalls and bayerite/Zn-Al LDH nanorods with micro/nanoscale hierarchical structures was fabricated on aluminum by using a simple hydrothermal reaction method after simple chemical modification. After processing, the wettability of the micro/nanoscale hierarchical structure surface can be changed from super-hydrophilic to super-hydrophobic with a CA as high as $167.3^{\circ}$ and a low sliding angle $<3^{\circ}$. The experiments of the static analysis of the freezing time and ice adhesion on different surfaces proved that the prepared films possess highly ice-phobicity. In addition, they remained active after ten ice-shedding events using an aggressive Spinner Coater technique, which shows the potential for protecting new, high-voltage overhead aluminum cables against excessive ice or snow accumulation. Further investigations have indicated that the ammonia concentration plays a major role in the surface structure, super-hydrophobicity and ice-phobcity. The present study opens up a very simple and economical way for the fabrication of super-hydrophobic and ice-phobic surfaces with the biomimic micro/nanostructures on engineering metallic materials.

\section{REFERENCES}

${ }^{1}$ N. Saleema, M. Farzaneh, Thermal effect on super-hydrophobic performance of stearic acid modified $\mathrm{ZnO}$ nanotowers, Applied
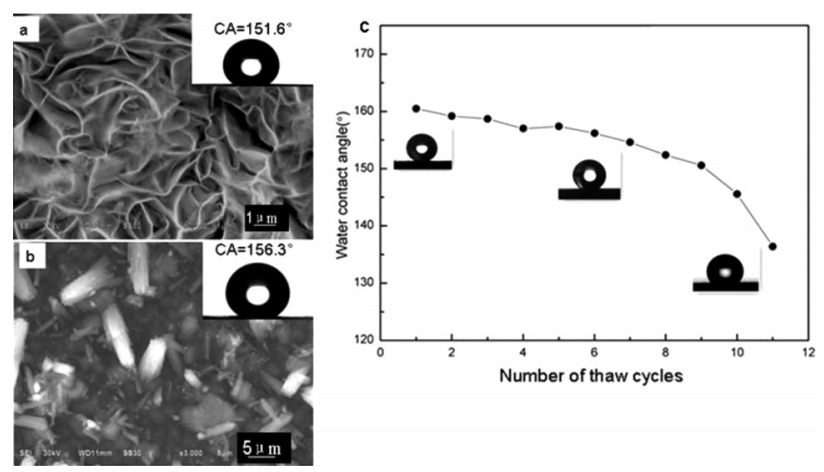

Figure 9: a) The SEM image of Zn-Al LDH films after six thaw cycles, b) the SEM image of bayerite/Zn-Al LDH films after six thaw cycles, c) the CA of bayerite/Zn-Al LDH films after different numbers of thaw cycles

Surface Science, 254 (2008) 9, 2690-2695, doi:10.1016/j.apsusc. 2007.10.004

${ }^{2}$ R. Menini, Z. Ghalmi, M. Farzaneh, Highly resistant ice-phobic coatings on aluminum alloys, Cold Regions Science And Technology, 65 (2011) 1, 65-69, doi:10.1016/j.coldregions.2010. 03.004

${ }^{3}$ A. Alizadeh, M. Yamada, R. Li, W. Shang, S. Otta, S. Zhong, L. Ge, A. Dhinojwala, K. R. Conway, V. Bahadur, A. J. Vinciquerra, B. Stephens, M. L. Blohm, Dynamics of ice nucleation on water repellent surfaces, Langmuir, 28 (2012) 6, 3180-3186, doi:10.1021/la2045256

${ }^{4}$ S. Lasher-Trapp, S. Anderson-Bereznicki, A. Shackelford, C. H. Twohy, J. G. Hudson, An Investigation of the Influence of Droplet Number Concentration and Giant Aerosol Particles upon Supercooled Large Drop Formation in Wintertime Stratiform Clouds, Journal of Applied Meteorology and Climatology, 47 (2008) 10, 2659-2678, doi:10.1175/2008jamc1807.1

${ }^{5}$ L. Vayssieres, N. Beermann, S.-E. Lindquist, A. Hagfeldt, Controlled Aqueous Chemical Growth of Oriented Three-Dimensional Crystalline Nanorod Arrays: Application to Iron(III) Oxides, Chemistry of Materials, 13 (2001) 2, 233-235, doi:10.1021/cm001202x

${ }^{6}$ I. A. Larmour, G. C. Saunders, S. E. J. Bell, Compressed Metal Powders that Remain Super-hydrophobic after Abrasion, ACS applied materials \& interfaces, 2 (2010) 10, 2703-2706, doi:10.1021/ am $100561 \mathrm{j}$

${ }^{7}$ S. Lu, Y. Chen, W. Xu, W. Liu, Controlled growth of super-hydrophobic films by sol-gel method on aluminum substrate, Applied Surface Science, 256 (2010) 20, 6072-6075, doi:10.1016/j.apsusc. 2010.03.122

${ }^{8}$ H. Zhang, W. Li, D. Cui, Z. Hu, L. Xu, Design of lotus-simulating surfaces: Thermodynamic analysis based on a new methodology, Colloids and Surfaces A: Physicochemical and Engineering Aspects, 413 (2012), 314-327, doi:10.1016/j.colsurfa.2012.01.036

${ }^{9}$ Z. W. Hu, W. Li, Preparation of super-hydrophobic Fe2O3 nanorod films with the tunable water adhesion, Journal Of Colloid And Interface Science, 376 (2012) 1, 245-249, doi:10.1016/j.jcis.2012. 01.023

${ }^{10}$ F. Xia, L. Jiang, Bio-Inspired, Smart, Multiscale Interfacial Materials, Advanced Materials, 20 (2008) 15, 2842-2858, doi:10.1002/ adma.200800836

${ }^{11}$ D. Quéré, Wetting and Roughness, Annual Review Of Materials Research, 38 (2008) 1, 71-99, doi:10.1146/annurev.matsci.38. 060407.132434

${ }^{12}$ H. Zhang, W. Li, H. Liu, D. Cui, Thermodynamic analysis on super-hydrophobicity based on the design of a pillar model, Soft Matter, 8 (2012) 40, 10360, doi:10.1039/c2sm26081f

${ }^{13}$ F. Shi, Z. Wang, X. Zhang, Combining a Layer-by-Layer Assembling Technique with Electrochemical Deposition of Gold Aggregates to 
Mimic the Legs of Water Striders, Advanced Materials, 17 (2005) 8, 1005-1009, doi:10.1002/adma.200402090

${ }^{14}$ X. Yu, Z. Wang, Y. Jiang, F. Shi, X. Zhang, Reversible pH-Responsive Surface: From Super-hydrophobicity to Super-hydrophilicity, Advanced Materials, 17 (2005) 10, 1289-1293, doi:10.1002/adma. 200401646

${ }^{15}$ W. Xu, H. Liu, S. Lu, J. Xi, Y. Wang, Fabrication of super-hydrophobic surfaces with hierarchical structure through a solution-immersion process on copper and galvanized iron substrates, Langmuir, 24 (2008) 19, 10895-10900, doi:10.1021/la800613d

${ }^{16}$ Z. Guo, J. Fang, L. Wang, W. Liu, Fabrication of super-hydrophobic copper by wet chemical reaction, Thin Solid Films, 515 (2007) 18, 7190-7194, doi:10.1016/j.tsf.2007.02.100

${ }^{17}$ L. Xu, L. M. Dong, W. Li, A simple "two foil" approach to the fabrication of hierarchical super-hydrophobic surfaces, Colloids and Surfaces A: Physicochemical and Engineering Aspects, 404 (2012), 12-16, doi:10.1016/j.colsurfa.2012.03.008

${ }^{18}$ J. Li, X. Liu, Y. Ye, H. Zhou, J. Chen, A facile solution-immersion process for the fabrication of super-hydrophobic surfaces with high water adhesion, Materials Letters, 66 (2012) 1, 321-323, doi:10.1016/j.matlet.2011.08.044

${ }^{19}$ W. Wu, M. Chen, S. Liang, X. Wang, J. Chen, F. Zhou, Super-hydrophobic surface from $\mathrm{Cu}-\mathrm{Zn}$ alloy by one step $\mathrm{O} 2$ concentration dependent etching, Journal Of Colloid And Interface Science, 326 (2008) 2, 478-482, doi:10.1016/j.jcis.2008.06.041

${ }^{20}$ Y. Zhang, J. Wu, X. Yu, H. Wu, Low-cost one-step fabrication of super-hydrophobic surface on Al alloy, Applied Surface Science, 257 (2011) 18, 7928-7931, doi:10.1016/j.apsusc.2011.03.096

${ }^{21}$ X. Zhang, M. Honkanen, M. Järn, J. Peltonen, V. Pore, E. Levänen, T. Mäntylä, Thermal stability of the structural features in the super-hydrophobic boehmite films on austenitic stainless steels, Applied Surface Science, 254 (2008) 16, 5129-5133, doi:10.1016/ j.apsusc.2008.02.053

${ }^{22}$ L. Li, V. Breedveld, D. W. Hess, Creation of super-hydrophobic stainless steel surfaces by acid treatments and hydrophobic film deposition, ACS Appl Mater Interfaces, 4 (2012) 9, 4549-4556, doi:10.1021/am301666c

${ }^{23}$ H. Chen, F. Zhang, S. Fu, X. Duan, In-Situ Microstructure Control of Oriented Layered Double Hydroxide Monolayer Films with Curved Hexagonal Crystals as Super-hydrophobic Materials, Advanced Materials, 18 (2006) 23, 3089-3093, doi:10.1002/adma.200600615

${ }^{24}$ F. Zhang, L. Zhao, H. Chen, S. Xu, D. G. Evans, X. Duan, Corrosion resistance of super-hydrophobic layered double hydroxide films on aluminum, Angewandte Chemie, International Edition in English, 47 (2008) 13, 2466-2469, doi:10.1002/anie.200704694

${ }^{25}$ S. He, Y. Zhao, M. Wei, X. Duan, Preparation of Oriented Layered Double Hydroxide Film Using Electrophoretic Deposition and Its Application in Water Treatment, Industrial \& Engineering Chemistry Research, 50 (2011) 5, 2800-2806, doi:10.1021/ie101152n

${ }^{26}$ L. Liu, J. Zhao, Y. Zhang, F. Zhao, Y. Zhang, Fabrication of superhydrophobic surface by hierarchical growth of lotus-leaf-like boehmite on aluminum foil, Journal Of Colloid And Interface Science, 358 (2011) 1, 277-283, doi:10.1016/j.jcis.2011.02.036

${ }^{27}$ Y. Guo, Q. Wang, T. Wang, Facile fabrication of super-hydrophobic surface with micro/nanoscale binary structures on aluminum substrate, Applied Surface Science, 257 (2011) 13, 5831-5836, doi:10.1016/j.apsusc.2011.01.114

${ }^{28}$ L. Cao, A. K. Jones, V. K. Sikka, J. Wu, D. Gao, Anti-icing superhydrophobic coatings, Langmuir, 25 (2009) 21, 12444-12448, doi:10.1021/la902882b

${ }^{29}$ S. A. Kulinich, M. Farzaneh, Ice adhesion on super-hydrophobic surfaces, Applied Surface Science, 255 (2009) 18, 8153-8157, doi:10.1016/j.apsusc.2009.05.033

${ }^{30}$ L. Yin, Q. Xia, J. Xue, S. Yang, Q. Wang, Q. Chen, In situ investigation of ice formation on surfaces with representative wettability, Applied Surface Science, 256 (2010) 22, 6764-6769, doi:10.1016/ j.apsusc.2010.04.086
${ }^{31}$ F. Wang, C. Li, Y. Lv, F. Lv, Y. Du, Ice accretion on super-hydrophobic aluminum surfaces under low-temperature conditions, Cold Regions Science And Technology, 62 (2010) 1, 29-33, doi:10.1016/ j.coldregions.2010.02.005

${ }^{32}$ S. A. Kulinich, M. Farzaneh, How wetting hysteresis influences ice adhesion strength on super-hydrophobic surfaces, Langmuir, 25 (2009) 16, 8854-8856, doi:10.1021/la901439c

${ }^{33}$ H. Saito, K. Takai, G. Yamauchi, Water- and ice-repellent coatings, Surface Coatings International, 80 (1997) 4, 168-171, doi:10.1007/ bf02692637

${ }^{34}$ V. F. Petrenko, S. Peng, Reduction of ice adhesion to metal by using self-assembling monolayers (SAMs), Canadian Journal of Physics, 81 (2003) 1-2, 387-393, doi:10.1139/p03-014

${ }^{35}$ P. Guo, Y. Zheng, M. Wen, C. Song, Y. Lin, L. Jiang, Ice-phobic/ anti-icing properties of micro/nanostructured surfaces, Advanced Materials, 24 (2012) 19, 2642-2648, doi:10.1002/adma.201104412

${ }^{36}$ X. Guo, S. Xu, L. Zhao, W. Lu, F. Zhang, D. G. Evans, X. Duan, One-step hydrothermal crystallization of a layered double hydroxide/alumina bilayer film on aluminum and its corrosion resistance properties, Langmuir, 25 (2009) 17, 9894-9897, doi:10.1021/ la901012w

${ }^{37}$ F. R. Costa, M. Saphiannikova, U. Wagenknecht, G. Heinrich, Layered Double Hydroxide Based Polymer Nanocomposites, 210 (2007), 101-168, doi:10.1007/12_2007_123

${ }^{38}$ J. Liu, X. Huang, Y. Li, K. M. Sulieman, X. He, F. Sun, Facile and large-scale production of $\mathrm{ZnO} / \mathrm{Zn}-\mathrm{Al}$ layered double hydroxide hierarchical heterostructures, The journal of physical chemistry. B, 110 (2006) 43, 21865-21872, doi:10.1021/jp064487v

${ }^{39}$ W. Li, X. Zhang, J. Yang, F. Miao, In situ growth of super-hydrophobic and ice-phobic films with micro/nanoscale hierarchical structures on the aluminum substrate, Journal Of Colloid And Interface Science, 410 (2013), 165-171, doi:10.1016/j.jcis.2013. 07.063

${ }^{40}$ Q. Li, V. Kumar, Y. Li, H. Zhang, T. J. Marks, R. P. H. Chang, Fabrication of $\mathrm{ZnO}$ Nanorods and Nanotubes in Aqueous Solutions, Chemistry of Materials, 17 (2005) 5, 1001-1006, doi:10.1021/ $\mathrm{cm} 048144 \mathrm{q}$

${ }^{41}$ D. P. Dubal, D. S. Dhawale, R. R. Salunkhe, V. J. Fulari, C. D. Lokhande, Chemical synthesis and characterization of Mn3O4 thin films for supercapacitor application, Journal of Alloys and Compounds, 497 (2010) 1-2, 166-170, doi:10.1016/j.jallcom.2010. 02.182

${ }^{42}$ M. Nosonovsky, Multiscale roughness and stability of super-hydrophobic biomimetic interfaces, Langmuir, 23 (2007) 6, 3157-3161, doi:10.1021/la062301d

${ }^{43}$ H. H. Liu, H. Y. Zhang, W. Li, Thermodynamic analysis on wetting behavior of hierarchical structured super-hydrophobic surfaces, Langmuir, 27 (2011) 10, 6260-6267, doi:10.1021/la200028x

${ }^{44}$ H. Zhang, W. Li, G. Fang, A new model for thermodynamic analysis on wetting behavior of super-hydrophobic surfaces, Applied Surface Science, 258 (2012) 7, 2707-2716, doi:10.1016/j.apsusc.2011.10.121

${ }^{45}$ E. Bormashenko, T. Stein, G. Whyman, Y. Bormashenko, R. Pogreb, Wetting properties of the multiscaled nanostructured polymer and metallic super-hydrophobic surfaces, Langmuir, 22 (2006) 24, 9982-9985, doi:10.1021/la061622m

${ }^{46}$ L. Jiang, Y. Zhao, J. Zhai, A Lotus-Leaf-like Super-hydrophobic Surface: A Porous Microsphere/Nanofiber Composite Film Prepared by Electrohydrodynamics, Angewandte Chemie, 116 (2004) 33, 4438-4441, doi:10.1002/ange.200460333

${ }^{47}$ X. Yao, Y. Song, L. Jiang, Applications of bio-inspired special wettable surfaces, Advanced Materials, 23 (2011) 6, 719-734, doi:10.1002/adma.201002689

${ }^{48}$ K. K. Varanasi, T. Deng, J. D. Smith, M. Hsu, N. Bhate, Frost formation and ice adhesion on super-hydrophobic surfaces, Applied Physics Letters, 97 (2010) 23, 234102, doi:10.1063/1.3524513 